\title{
A New Characterization Parameter of out-of-plane Constraint for $C(T)$ Specimens
}

\author{
Zhao Lingyan $^{1, a}$, Cui Yinghao ${ }^{2}$ and Yang Fuqiang ${ }^{1}$ \\ ${ }^{1}$ School of Science, Xi'an University of Science and Technology, Xi'an 710054, China \\ ${ }^{2}$ School of Mechanical Engineering, Xi'an University of Science and Technology, Xi'an 710054, China
}

\begin{abstract}
As the resistance of structures against the crack-tip plastic deformation, constraints has attracted much attention in the research of material fracture behaviour. In order to increase the accuracy of structural integrity assessment, many characterization parameters of in-plane and out-of-plane constraints have been considered and proposed in the last few decades. Threedimensional finite element analyses have been conducted for five $\mathrm{C}(\mathrm{T}) 50$ specimens with different out-of-plane constraint. The distributions of four constraint parameters $\left(\sigma_{22} / \sigma_{0}, T_{\mathrm{z}}, h\right.$ and $D_{\mathrm{p}}$ ) along crack fronts were calculated. To characterize the out-of-plane constraint, the capability of constraint parameters such as $\sigma_{22} / \sigma_{0}, T z, h$ and $D_{\mathrm{p}}$ were analyzed and compared. Results show that, compared with the three constraint parameters $\left(\sigma_{22} / \sigma_{0}, T_{z}\right.$ and $\left.h\right)$ based on crack-tip stress fields, the parameter $D_{\mathrm{p}}$ based on crack-tip equivalent plastic strain is more sensitive to out-of-plane constraint, and may effectively characterize the out-of-plane constraint.
\end{abstract}

\section{Introduction}

As the resistance of structures against the crack-tip plastic deformation, constraints has attracted much attention in the research of material fracture behaviour. Constraints can be divided into in-plane constraint and out-of-plane constraint. The in-plane constraints such as the crack length relate to the specimen dimension in the direction of growing crack. The out-of-plane constraints such as the specimen thickness relate to the specimen dimension parallel to crack front. In order to increase the accuracy of structural integrity assessment, many characterization parameters of in-plane and out-ofplane constraints have been considered and proposed, such as $T$-stress[1], $Q[2], A_{2}[3], T_{\mathrm{z}}[4,5]$, stress triaxiality factor $h[6]$ and $A_{\mathrm{p}}[7,8]$ etc.

In this work, $\sigma_{22}$ is the stress component at crack tip in the direction parallel to the crack propagation direction, and it is the most common parameter for charactering the crack-tip driving force. Usually, the stress $\sigma_{22}$ is normalized by the yield strength $\sigma_{0}$, then a constraint parameter can be described by $\sigma_{22} / \sigma_{0}$. And the numerical solutions of $\sigma_{22} / \sigma_{0}$ were obtained through detailed 3D finiteelement (FE) calculations.

The constraint parameter $T_{\mathrm{z}}$ introduced by Guo[4,5] is defined as the ratio of out-of-plane stress $\left(\sigma_{\mathrm{zz}}\right)$ to sum of the in-plane stresses $\left(\sigma_{\mathrm{xx}}\right.$ and $\left.\sigma_{\mathrm{yy}}\right)$, and it can characterize the 3D crack-tip stress fields:

$$
T_{Z}=\frac{\sigma_{z z}}{\sigma_{x x}+\sigma_{y y}}
$$

\footnotetext{
${ }^{a}$ Corresponding author : gloomy2@foxmail.com
} 
The stress triaxiality factor $h$ is defined as the ratio of the hydrostatic stress $\sigma_{\mathrm{m}}$ to the von Mises stress $\sigma_{\mathrm{e}}$ :

$$
h=\frac{\sigma_{m}}{\sigma_{e}}=\frac{\sigma_{1}+\sigma_{2}+\sigma_{3}}{3 \sqrt{\frac{1}{2}\left[\left(\sigma_{1}-\sigma_{2}\right)^{2}+\left(\sigma_{2}-\sigma_{3}\right)^{2}+\left(\sigma_{3}-\sigma_{1}\right)^{2}\right]}}
$$

where $\sigma_{\mathrm{i}}(i=1,2$ and 3$)$ are the principal stresses. The factor $h$ incorporates both in-plane and out-ofplane principal stresses. Thus, it may have a capability to describe both in-plane and out-of-plane constraint effects.

Based on crack-tip equivalent plastic strain, a new characterization parameter $D_{\mathrm{p}}$ of out-of-plane constraint was defined as follows:

$$
D_{p}=\frac{D_{P E E Q}}{D_{\text {ref }}}
$$

where $D_{\text {PEEQ }}$ is the gradient of equivalent plastic strain $\left(\varepsilon_{\mathrm{p}}\right)$ in the middle-plane area surrounded by a specific $\varepsilon_{\mathrm{p}}$ isoline along a evaluated specimen crack front, and $D_{\text {ref }}$ is the $\varepsilon_{\mathrm{p}}$ gradient in the middleplane area surrounded by a specific $\varepsilon_{\mathrm{p}}$ isoline along the crack front of a standard reference specimen with high constraint level at fracture.

\section{Finite element modelling}

\subsection{Specimen model}

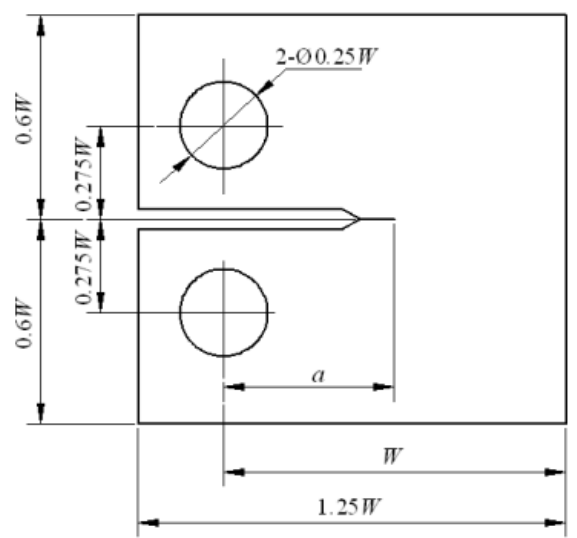

Figure1. Geometry of $\mathrm{C}(\mathrm{T})$ specimen $(W=50 \mathrm{~mm})$

A compact tension (CT) specimen with a constant load was used to measure SCC growth rate in high temperature water environment [9]. Five types of $\mathrm{C}(\mathrm{T})$ specimens (specimen width $W=50 \mathrm{~mm}$ ) with thickness-to-width ratio $B / W=0.0625,0.125,0.25,0.5$ and 1 were chosen, and their relative crack length $a / W=0.5$ after pre-cracking. The geometry and size configurations of a $\mathrm{C}(\mathrm{T}) 50$ specimen is shown in figure 1 . It can be considered that the out-of-plane constraints were changed by the changing specimen thickness $B$, and the specimen sizes are shown in table 1 .

The calculated results of fracture toughness are also listed in table 1 . The stress-strain field distributions along crack fronts were calculated at the same average J-integral value of $J_{\text {ave }}=20 \mathrm{~kJ} / \mathrm{m}^{2}$ along the specimen crack fronts with different out-of-plane constraints, and the maximum values of Jinternal $J_{\max }$ at the crack fronts mid-point were also listed. The values of fracture toughness $K_{\max }$ in table 1 were calculated from $J_{\max }$ by equation 4 .

$$
K_{\max }=\sqrt{J_{\max } \frac{E}{1-v^{2}}}
$$


where, $E$ is the Young's modulus and $v$ is the Poisson's ratio.

Table 1. $\mathrm{C}(\mathrm{T})$ specimen sizes and the calculated results of fracture toughness

\begin{tabular}{ccccccc}
\hline Specimen & $a / W$ & $B(\mathrm{~mm})$ & $B / W$ & $P(\mathrm{kN})$ & $K_{\max }\left(\mathrm{MPa} \cdot \mathrm{m}^{1 / 2}\right)$ & $J_{\max }\left(\mathrm{kJ} \cdot \mathrm{m}^{-2}\right)$ \\
\hline & 3.125 & 0.0625 & 1.83 & 74.78 & 23.67 \\
$\mathrm{C}(\mathrm{T}) 50$ & 6.25 & 0.125 & 3.7 & 74.56 & 23.53 \\
& 0.5 & 12.5 & 0.25 & 7.57 & 74.27 & 23.35 \\
& & 25 & 0.5 & 15.6 & 74.05 & 23.21 \\
& & & 1 & 32.4 & 74.02 & 23.19 \\
\hline
\end{tabular}

\subsection{Material model}

The pressure vessel steel $22 \mathrm{NiMoCr} 3-7$ is investigated in this paper, and its non-linear relationship between stress and strain beyond yield can be described by Ramberg-Osgood equation [10]:

$$
\frac{\varepsilon}{\varepsilon_{0}}=\frac{\sigma}{\sigma_{0}}+\alpha\left(\frac{\sigma}{\sigma_{0}}\right)^{n}
$$

where $\varepsilon$ is the strain, including elastic and plastic strain. $\sigma$ is the total stress; $\varepsilon_{0}$ is the yield strain of the material, $\sigma_{0}$ is the yield stress of the material, and $n$ is the strain hardening exponent of the material, $\alpha$ is the material offset coefficient.

The mechanical properties data and the Ramberg-Osgood constitutive parameters of $22 \mathrm{NiMoCr} 3-7$ steel at $-60^{\circ} \mathrm{C}$ are given in table 2 .

Table 2. Mechanical properties of $22 \mathrm{NiMoCr} 3-7$ steel at $-60^{\circ} \mathrm{C}[11]$

\begin{tabular}{cccccc}
\hline Material & $\begin{array}{c}\text { Young's } \\
\text { modulus } \\
E(\mathrm{MPa})\end{array}$ & $\begin{array}{c}\text { Poison ratio } \\
v\end{array}$ & $\begin{array}{c}\text { Yield stress } \\
\sigma_{0}(\mathrm{MPa})\end{array}$ & $\begin{array}{c}\text { Hardening } \\
\text { exponent } \\
n\end{array}$ & $\begin{array}{c}\text { Hardening } \\
\text { parameter } \\
\alpha\end{array}$ \\
\hline $22 \mathrm{NiMoCr3-7}$ & 215000 & 0.3 & 517 & 3.7 & 6.2 \\
\hline
\end{tabular}

\subsection{FE Model}

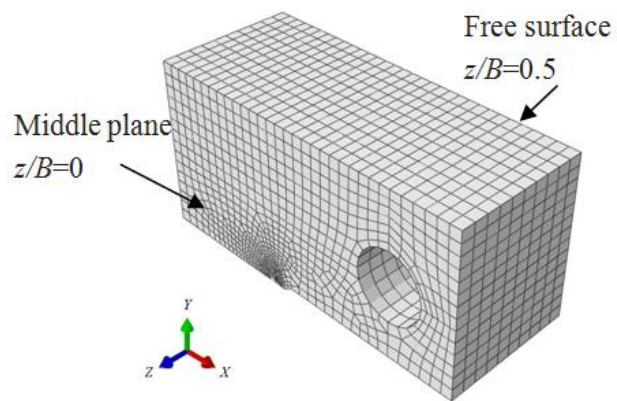

(a) Mesh of global model

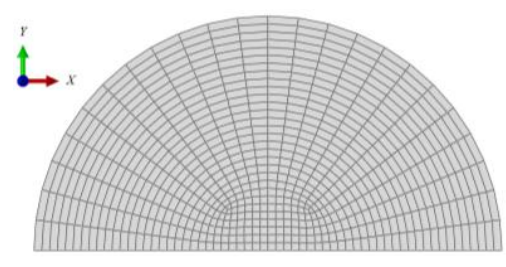

(b) Mesh around crack front

Figure 2. The global model mesh and mesh around crack front of $\mathrm{C}(\mathrm{T}) 50$ specimen with $B=25 \mathrm{~mm}$ and $a / W=0.5$

Five 3D FE models in table 1 were built by the commercial finite element code ABAQUS [12]. The eight-node isoperimetric elements with reduced integration (C3D8R) were used for all models. To reduce the computation time, considering the loading and geometry symmetry, only $1 / 4$ th of the specimen was modeled. The symmetry boundary conditions were applied on the un-cracked ligaments. The FE model meshes of $\mathrm{C}(\mathrm{T}) 50$ specimen with $B=25 \mathrm{~mm}$ and $a / W=0.5$ are shown in figure 2 . 


\section{Results and Discussion}

To characterize the out-of-plane crack-tip constraints, the capability of constraint parameters such as $\sigma_{22} / \sigma_{0}, T \mathrm{z}, h$ (based on crack-tip stress fields) and $D_{\mathrm{p}}$ (based on crack-tip equivalent plastic strain) were analyzed and compared. The parameters $\sigma_{22} / \sigma_{0}, T_{\mathrm{z}}$ and $h$ were calculated and evaluated at $r=2 J / \sigma_{0}$ and $\theta=0$ by using equations 1 and 2 , respectively.

The reference $\varepsilon_{\mathrm{p}}$ gradient $D_{\text {ref }}$ in equation 3 was calculated at the area surrounded by the $\varepsilon \mathrm{p}=0.002$ isoline in the middle plane of a standard reference $\mathrm{C}(\mathrm{T}) 50$ specimen with $B / W=0.5$ and $a / W=0.5$ in Table 1, which is with high constraint.

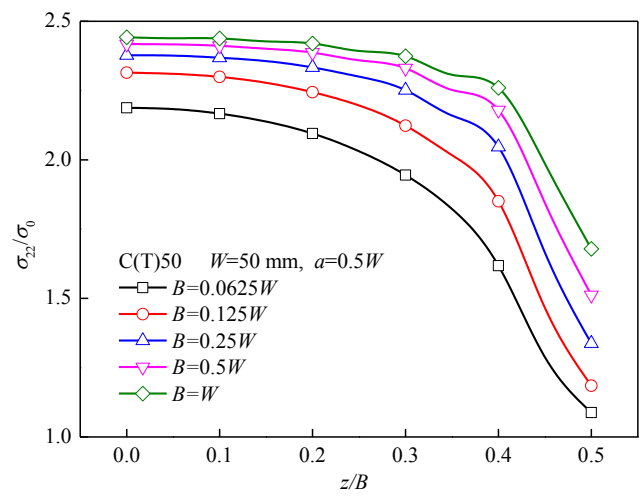

Figure3. Distributions of constraint parameter $\sigma_{22} / \sigma_{0}$ ahead of crack fronts

Figures 3-6 show the distributions of the four constraint parameters for $\mathrm{C}(\mathrm{T})$ specimens with the same $a / W=0.5$ (same in-plane constraint) and different B (different out-of-plane constraint). The constraint parameters are plotted against the normalized specimen thickness $z / B$, and the $z / B=0$ is the middle plane and the $z / B=0.5$ is the free surface of the specimens.

It can be seen from figures 3 and 4 that the centre region (from $z / B=0$ to 0.4 ) of all specimens has higher constraint, and the surface region (near $z / B=0.5$ ) has lower constraint. The normalized constraint parameter $\sigma_{22} / \sigma_{0}$ and $T_{\mathrm{z}}$ in the centre region have very small variation with increasing specimen thickness $\mathrm{B}$. This implies that the parameters $\sigma_{22} / \sigma_{0}$ and $T_{\mathrm{z}}$ are insensitive to out-of-plane constraint and can not effectively characterize it.

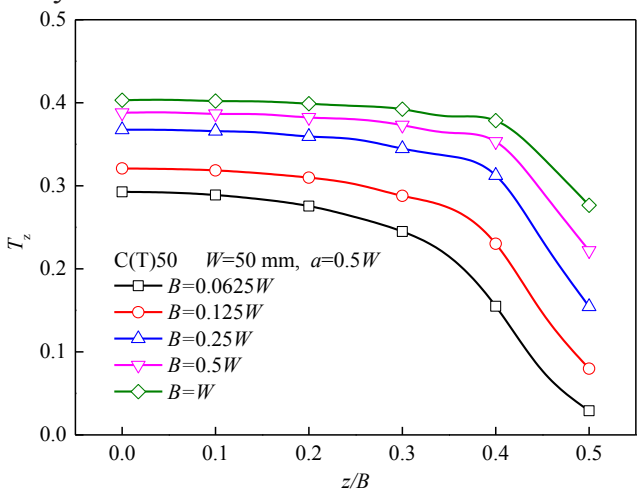

Figure 4. Distributions of constraint parameter $T_{\mathrm{z}}$ ahead of crack fronts 


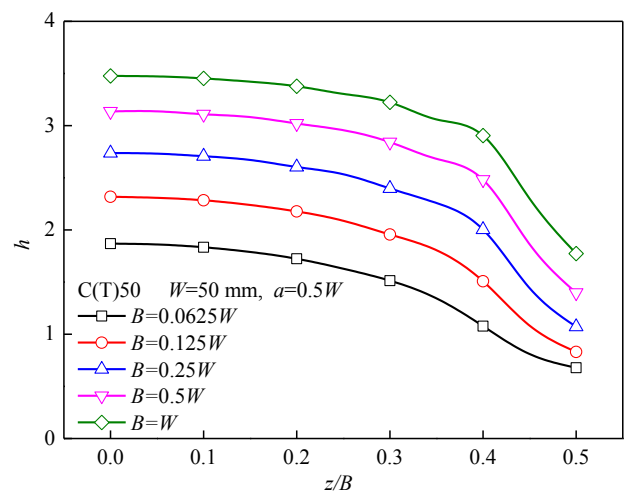

Figure 5. Distributions of constraint parameter $h$ ahead of crack fronts

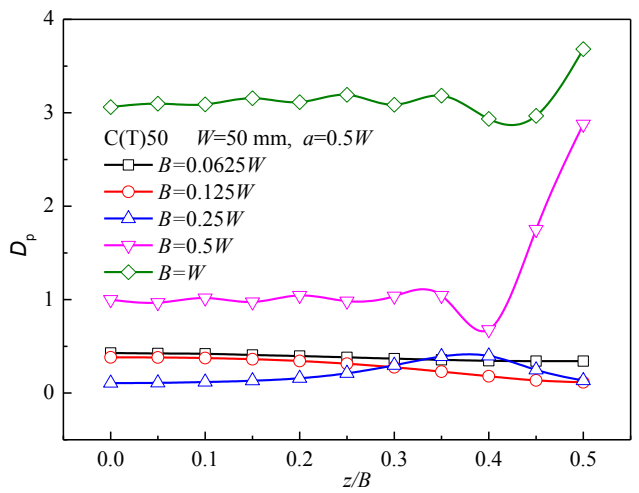

Figure 6. Distributions of constraint parameter $D_{\mathrm{p}}$ ahead of crack fronts

In figure 5, the parameters $h$ increases with the increasing thickness $\mathrm{B}$, which indicates that the parameters $h$ is sensitive to out-of-plane constraint effect induced by thickness B. Figure 6 shows that the parameter $D_{\mathrm{p}}$ significantly increases with the increasing thickness B (the increase of $D_{\mathrm{p}}$ implies the decrease of constraint). The greater values of $D_{\mathrm{p}}$ mean that the thicker specimens surface regions (near $z / B=0.5$ ) have lower constraints and lead to more deformations. This implies that the parameter $D_{\mathrm{p}}$ may more efficiently capture the out-of-plane constraint effect than the three parameters $\sigma_{22} / \sigma_{0}, T_{\mathrm{z}}$ and $h$.

\section{Conclusion}

Three-dimensional finite element analyses have been conducted for five $\mathrm{C}(\mathrm{T}) 50$ specimens with different out-of-plane constraint. The distributions of four constraint parameters $\left(\sigma_{22} / \sigma_{0}, T_{\mathrm{z}}, h\right.$ and $\left.D_{\mathrm{p}}\right)$ along crack fronts were calculated. Results show that, compared with the three constraint parameters $\left(\sigma_{22} / \sigma_{0}, T_{\mathrm{z}}\right.$ and $\left.h\right)$ based on crack-tip stress fields, the parameter $D_{\mathrm{p}}$ based on crack-tip equivalent plastic strain is sensitive to out-of-plane constraint, and may effectively characterize the out-of-plane constraint.

\section{Acknowledgements}

This work is financially supported by the National Natural Science Foundation of China (Grant no. is 11502195).

\section{References}


1. S. G. Larsson, A. J. Carlsson, J. Mech. Phys. Solids., 21, 263 (1973)

2. N. P. O'Dowd, C. F. Shih, J. Mech. Phys. Solids., 40, 939 (1992)

3. Y. J. Chao, S. Yang, M. A. Sutton, J. Mech. Phys. Solids., 42, 629 (1994)

4. W. L. Guo, Engng. Fract. Mech., 46, 93 (1993)

5. W. L. Guo, Engng. Fract. Mech., 46, 105 (1993)

6. H. Clausmeyer, K. Kussmaul, E. Roos, Appl. Mech. Rev., 44, 77 (1991)

7. J. Yang, G. Z. Wang, F. Z. Xuan, S. T. Tu, Eng. Fract. Mech., 115, 296 (2014)

8. J. Yang, G. Z. Wang, F. Z. Xuan, S. T. Tu, Fatigue Fract. Eng. Mater. Struct., 37, 132 (2014)

9. Y. J. Kim, J. S. Kim, S. M. Cho, Y. J. Kim, Eng. Fract. Mech., 71, 1203 (2004)

10. L. Y. Zhao, H. Xue, F. Q. Yang, Y. H. Suo, Frat. Integrita Strutr., 29, 410 (2014)

11. J. Hebel, J. Hohe, V. Friedmann, D. Siegele, Int. J. Fract., 146, 173 (2007)

12. ABAQUS Inc, ABAQUS/Standard User's Manual Version 6.14 (2015) 